\title{
Sweat sodium losses of professional rugby players with and without a history of cramp
}

\author{
K. E. Black ${ }^{1}$, K. Fairbairn ${ }^{1,2}$, S. Macdonald ${ }^{1}$ and S. Cameron ${ }^{1}$ \\ ${ }^{1}$ Department of Human Nutrition, University of Otago, Dunedin, New Zealand and ${ }^{2}$ Otago Rugby Football Union, \\ Dunedin, New Zealand
}

Skeletal muscle cramps have been reported by numerous athletes both during and after exercise. Serum electrolyte and fluid disturbances have been associated with the development of muscle cramps in certain clinical conditions ${ }^{(1)}$. This has led some authors to suggest that exercise-induced muscle cramps are related to an imbalance in serum electrolytes caused by excessive sweat electrolyte losses ${ }^{(2)}$. As the major electrolyte of sweat is sodium, cramping has been linked to high sweat sodium losses. A study on American footballers who had previously suffered from heat cramps showed a higher sweat sodium concentration amongst these players ${ }^{(3)}$.

This study was designed to observe the sweat sodium losses between professional rugby union players in New Zealand who had previously suffered from cramp and those who had never reported any episode of cramping.

Ethical approval was obtained from the university ethics committee before recruitment was undertaken. Thirty professional rugby union players volunteered and provided informed consent before participating in the study. Body mass was measured prior to the training sessions. The training consisted of an RPM spin class on stationery bikes. The training session lasted 60 min and took place with atmospheric temperature and relative humidity $14^{\circ} \mathrm{C}$ with relative humidity $91 \%$.

Data were analysed using SPSS version 16.0. Differences between the two groups were determined using independent $t$-tests, with significance set at $P<0.05$.

Mean sweat rates for the crampers was 0.98 (SD 0.44) litre/h compared to the non-crampers whose sweat rate was 1.1 (SD 0.40 ) litre/h. There was no significant difference between the groups $(P=0.853)$. Nor was there any significant difference in the sweat sodium concentrations between the crampers and the non-crampers $(P=0.235)$. With the sweat sodium of the crampers being $40(\mathrm{SD} 6) \mathrm{mmol} / \mathrm{l}$ and the non-crampers being 45 (SD 15 ) $\mathrm{mmol} / \mathrm{l}$.

These sweat sodium concentrations of the present study differ from those previously reported in studies comparing crampers and non-crampers ${ }^{(3)}$. The findings of the present study do not support the theory of sweat sodium losses leading to serum electrolyte imbalances and eventual muscle cramps. Other theories regarding muscle fatigue have been postulated as a potential cause of muscle cramps during and after exercise ${ }^{(4)}$. However, the small subset of players in this study who had previously suffered from cramp makes it difficult to draw firm conclusions.

1. McGee SR (1990) Muscle cramps. Arch Intern Med 150, 511-518.

2. Schwellnus MP, Nicol J, Laubscher R et al. (2004) Serum electrolyte concentrations and hydration status are not associated with exercise associated muscle cramping (EAMC) in distance runners. Br J Sports Med 38, 488-492.

3. Stofan JR, Zachwieja JJ, Horswill CA et al. (2005) Sweat and sodium losses in NCAA football players: a precursor to heat cramps? Int J Sport Nutr Exerc Metab 15, 641-652.

4. Bergeron MF (2008) Muscle cramps during exercise - is it fatigue or electrolyte deficit? Curr Sports Med Rep 7, S50-S55. 